\title{
Linchpin Synthons: Metalation of Aryl Bromides Bearing a Potassium Trifluoroborate Moiety
}

\author{
Gary A. Molander ${ }^{*}$ and Noel M. Ellis \\ Roy and Diana Vagelos Laboratories, Department of Chemistry, University of Pennsylvania, \\ Philadelphia, Pennsylvania 19104-6323
}

\begin{abstract}
Aryl bromides bearing a potassium trifluoroborate moiety were subjected to lithium-halogen exchange at low temperature using a variety of alkyllithium reagents. A number of different electrophiles were evaluated in their reactions with the aryllithiums produced therein. Under carefully optimized conditions, potassium bromophenyl trifluoroborates afforded good to excellent yields of the corresponding alcohols (64-94\% isolated yield) when aldehydes or ketones were used as the electophilic partner. Esters were unfortunately found tobe unreactive.
\end{abstract}

Metal-halogen exchange reactions have had a rich history in synthetic organic chemistry, specifically with respect to the formation of C-C bonds. ${ }^{1}$ However, the tendency of boronate esters and boranes to act as a Lewis acid toward alkyllithiums and Grignard reagents has prevented the functionalization of boron-containing compounds via a metal-halogen exchange route. To date, there exists only one report in which a metal-halogen exchange, specifically a magnesium-halogen exchange, was used in the presence of a boron-containing functional group. ${ }^{2}$ That method employed expensive iodoaryl pinacol boronates as substrates. Concurrent to that development, our continuing interest in the chemistry of potassium organotrifluoroborates led us to speculate on their use in metal-halogen exchange reactions. In recent years, organotrifluoroborates have proven to be valuable synthetic intermediates, participating in a range of palladium-catalyzed cross-couplings, $3 \mathrm{a}, 4$ rhodium-catalyzed conjugate additions, ${ }^{5}$ and allylations of aldehydes 6 as well as $N$ - toluenesulfonylimines. ${ }^{7}$ Moreover, potassium organotrifluoroborate salts are easily prepared by the addition of inexpensive $\mathrm{KHF}_{2}$ to various organoboron intermediates, ${ }^{8}$ and they are air- and moisture-stable crystalline solids that are readily isolated. ${ }^{3,8}$ Metalation of organotrifluoroborates would give rise to useful bimetallic linchpins capable of sequential functionalization at each of the two metal centers (Scheme 1), thus increasing molecular complexity in a convergent manner. In this Note we report the realization of these bimetallic linchpin reagents using the lithiumhalogen exchange of potassium bromophenyl trifluoroborates.

Initial studies focused on the lithium-halogen exchange of potassium $p$-bromophenyl trifluoroborate (1). While methanol, acetonitrile, and acetone are known to be excellent solvents for a wide array of potassium organotrifluoroborates, ${ }^{3}$ all of these commonly employed solvents are far too acidic to remain inert under the strongly basic conditions of the metal-halogen exchange reaction. Out of necessity, it was discovered that THF also serves as an excellent solvent for a number of potassium organotrifluoroborates. Because of its ease of workup and known spectral properties, potassium phenyl trifluoroborate (2) ${ }^{9}$ made a logical target to probe the lithium-halogen exchange reaction of $\mathbf{1}$. Unfortunately, early attempts at the reaction of 1 with 1 equiv of $n$-BuLi in THF at $-78^{\circ} \mathrm{C}$, followed by a variety of aqueous 
quenches (Scheme 2), met with little success. Although the oils isolated from these early reactions were shown to contain "ate" complexes of boron by ${ }^{11}$ B NMR, standard precipitation in diethyl ether did not yield a white crystalline solid, even though both ${ }^{1} \mathrm{H}$ and ${ }^{13} \mathrm{C}$ spectra of the crude oils were also consistent with $\mathbf{2}$. Changing the workup protocol improved the situation to some degree. Thus, an aqueous quench with satd $\mathrm{KHF}_{2}(\mathrm{aq})$ led to a modest yield of $\mathrm{KPhBF}_{3}(\sim 30 \%)$. Undaunted by these disappointing initial results, we proceeded to investigate the quenching of the presumed organolithium intermediate with carbon electrophiles. In fact, utilization of cyclohexanecarboxaldehyde (3) as the electrophile led to the isolation of a white crystalline solid whose spectra were entirely consistent with the desired product (4) in 79\% yield (Scheme 2).

Careful optimization studies were carried out on the preparation of alcohol 6 (Table 1). Variation of solvents (DME or THF) and molarity revealed that the best results were consistently obtained at $0.1 \mathrm{M}$ in THF (85\% yield). Though additives that decrease the aggregation state of $n$-BuLi have been shown to increase the rates of lithium-halogen exchange reactions, ${ }^{10}$ addition of 1 equiv of TMEDA gave $\mathbf{6}$ in only $30 \%$ isolated yield. Variation of lithium sources showed that $n$-BuLi was preferable to $s$-BuLi (40\% yield) and $t$-BuLi (22\% yield). Experiments to determine the time required for lithium-halogen exchange are summarized in Table 1. Remarkably, it was found that the best yields were obtained when the introduction of the electrophile was delayed as much as $1 \mathrm{~h}$ following the addition of $n$-BuLi at $-78{ }^{\circ} \mathrm{C}$ ( $87 \%$ yield). Longer delays led to only small decreases in isolated yield. Last, but not least, it was found while optimizing the reaction of $\mathbf{2 3}$ to $\mathbf{2 4}$ (eq 1) that the $\mathrm{KHF}_{2}$ (aq) quench proceeded very rapidly, with times longer than 10 min leading to diminished yields of the product.

In general, lithium-halogen exchanges followed by addition to aliphatic or aromatic aldehydes gave good to excellent yields of the secondary alcohols (Table 2, entries 1-4). As for $\alpha, \beta$ unsaturated aldehydes, reaction of acrolein (11) provided solely the 1,2-addition product (12). Ketones 13 and 15 underwent smooth conversion to tertiary alcohols 14 and 16, respectively. Esters, however, proved unreactive under the standard reaction conditions. Other classes of electrophiles also proved suitable to the method. Silylation with TMSCl (17) provided silyl trifluoroborate 18 in good yield. Iodination using $\mathrm{I}_{2}(\mathbf{1 9})$ proceeded as expected to provide $p$-iodophenyl trifluoroborate (20). Finally, phenylisocyanate (21) reacted to give the amide-containing trifluoroborate (22).

Less general were the reactions of meta-substituted potassium bromoaryl trifluoroborates and various heteroaryl bromides. TMSCl (17) was found to react with the aryllithium arising from $\mathbf{2 3}$ to give $\mathbf{2 4}$ in good yield when $t$-BuLi was used as the metallating agent (Scheme 3). As a rule, however, the use of other electrophiles was hindered by the low crystallinity of the products, which frequently gave oils that could not be further purified. In these cases, direct conversion of the crude potassium trifluoroborate to the tetrabutylammonium trifluoroborate was possible, but did not effect a satisfactory purification of the products. ${ }^{11}$ Various heteroaryl bromides were explored but were found to give results analogous to those using $\mathbf{2 3}$.

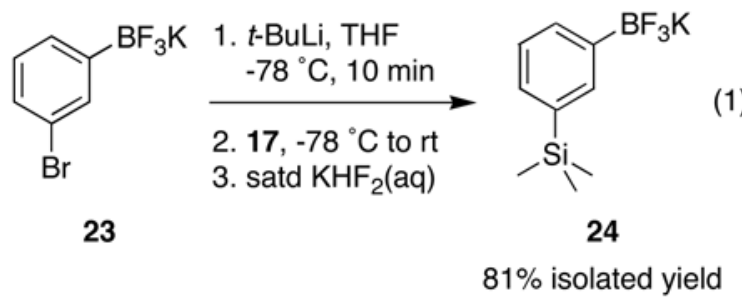

J Org Chem. Author manuscript; available in PMC 2008 August 8. 
In summary, a new entry into functionalized boron compounds has been developed via the lithium-halogen exchange reaction of potassium organotrifluoroborates. The method is less expensive and simpler than existing protocols. ${ }^{2}$ Moreover, the trifluoroborates produced according to the method presented here may be cross-coupled following previously developed protocols for the Suzuki-Miyaura cross-coupling of aryl trifluoroborates. ${ }^{12}$ Further studies aimed at widening the scope of this method will be the subject of future communications.

\section{Experimental Section}

\section{General Experimental Procedure for the Lithium-Halogen Exchange of Potassium Bromoaryl Trifluoroborates. Preparation of Potassium 4-(1-Hydroxypropyl)phenyl Trifluoroborate (10)}

To an oven-dried round bottom flask $(50 \mathrm{~mL})$ was added $p$-bromophenyl trifluoroborate $(262$ $\mathrm{mg}, 1.0 \mathrm{mmol}$ ). The flask was evacuated and back-filled with $\mathrm{N}_{2}$ three times before adding freshly distilled THF $(10 \mathrm{~mL})$. A Dry Ice/acetone bath was then used to cool the reaction to $-78^{\circ} \mathrm{C}$ and $n$-BuLi $(1.0 \mathrm{mmol})$ was added dropwise. The reaction was then left to stir at -78 ${ }^{\circ} \mathrm{C}$ for $1 \mathrm{~h}$, during which time an insoluble salt precipitated. Next, neat propionaldehyde (58 $\mathrm{mg}, 1.0 \mathrm{mmol}$ ) was added dropwise, and stirring was continued for an additional $10 \mathrm{~min}$ at -78 ${ }^{\circ} \mathrm{C}$. After warming to rt, the reaction was stirred at $\mathrm{rt}$ for $30 \mathrm{~min}$, then satd $\mathrm{KHF}_{2}$ (aq) (390 mg, $5.0 \mathrm{mmol}$ ) was added, and the reaction was stirred at $\mathrm{rt}$ for $10 \mathrm{~min}$. Evaporation of the solvents in vacuo was followed by drying at 0.05 torr for a minimum of $6 \mathrm{~h}$. Acetone extraction $(3 \times$ $20 \mathrm{~mL}$ ) and filtration of the solids gave a solution of the product trifluoroborate in acetone. Reduction of the solvent followed by dropwise addition of $\mathrm{Et}_{2} \mathrm{O}$ led to precipitation of the product. The product was then filtered, collected, and dried overnight at 0.05 torr to afford potassium 4-(1-hydroxypropyl)phenyl trifluoroborate $(212 \mathrm{mg}, 88 \%) . \mathrm{mp}>250{ }^{\circ} \mathrm{C}$. ${ }^{1} \mathrm{H}-\mathrm{NMR}$ $\left(500 \mathrm{MHz}, \mathrm{DMSO}-d_{6}\right): 7.26(\mathrm{~d}, J=7.8 \mathrm{~Hz}, 2 \mathrm{H}), 7.0(\mathrm{~d}, J=7.8 \mathrm{~Hz}, 2 \mathrm{H}), 4.82(\mathrm{~m}, 1 \mathrm{H}), 4.31$ $(\mathrm{m}, 1 \mathrm{H}), 1.58(\mathrm{~m}, 2 \mathrm{H}), 0.80(\mathrm{t}, J=7 \mathrm{~Hz}, 3 \mathrm{H}) ;{ }^{13} \mathrm{C}-\mathrm{NMR}\left(125.8 \mathrm{MHz}, \mathrm{DMSO}-d_{6}\right): 142.3,130.9$, 123.9, 74.2, 32.1, 10.3; ${ }^{19} \mathrm{~F}-\mathrm{NMR}\left(471 \mathrm{MHz}, \mathrm{DMSO}-d_{6}\right):-139.2 ;{ }^{11} \mathrm{~B}-\mathrm{NMR}(128.37 \mathrm{MHz}$, DMSO- $\left.d_{6}\right): 3.37$; IR $(\mathrm{KBr})=3403,2964 \mathrm{~cm}^{-1}$; HRMS (ESI) calcd. for $\mathrm{C}_{9} \mathrm{H}_{11} \mathrm{OBF}_{3}\left(\mathrm{M}^{-}\right)$ 203.0855, found 203.0845 .

\section{Supplementary Material}

Refer to Web version on PubMed Central for supplementary material.

\section{Acknowledgements}

This work was generously supported by the National Institutes of Health (GM35249), Amgen, and Merck Research Laboratories. N.M.E acknowledges the generous financial support of the University of Pennsylvania through a Douty Fellowship. We would also like to extend thanks to Frontier Scientific for their generous donation of boronic acids and Dr. Rakesh Kohli for high-resolution mass spectrometry.

\section{References}

1. (a) Bailey WF, Patricia JJ. J Organomet Chem 1988;352:1-46. (b) Knochel P, Dohle W, Gommerman N, Kneisel FF, Kopp F, Korn T, Sapountzis I, Vu VA. Angew Chem, Int Ed 2003;42:4302-4320. (c) Parham WE, Bradsher CK. Acc Chem Res 1982;15:300-305. (d) Rogers HR, Houk J. J Am Chem Soc 1982;104:522-525. (e) Rieke RD, Lee J, Velarde-Ortiz R, Guijarro A, Wurst JR. J Org Chem 2000;65:5428-5430. [PubMed: 10993378] (f) Slocum DW, Carroll A, Dietzel P, Eilerman S, Culver JP, McClure B, Brown S, Holman RW. Tetrahedron Lett 2006;47:865-868. (g) Oshima K, Inoue A, Kitagawa K, Shinokubo H. J Org Chem 2001;66:4333-4339. [PubMed: 11397172]

2. Knochel P, Baron O. Angew Chem Int, Ed 2005;44:3133-3135.

3. For reviews of organotrifluoroborate salts, see: (a) Molander GA, Figueroa R. Aldrichimica Acta 2005;38:49-56. (b) Darses S, Genêt J-P. Eur J Org Chem 2003:4313-4327.

4. (a) Molander GA, Felix LA. J Org Chem 2005;70:3950-3956. [PubMed: 15876083] (b) Molander GA, Figueroa R. Org Lett 2006;8:75-78. [PubMed: 16381571] (c) Cella R, Cunha RLOR, Reis AES, 
Pimenta DC, Klitzke CF, Stefani HA. J Org Chem 2006;71:244-250. [PubMed: 16388643] (d) Molander GA, Sommers EM, Baker SR. J Org Chem 2006;71:1563-1568. [PubMed: 16468806] (e) Molander GA, Yokoyama Y. J Org Chem 2006;71:2493-2498. [PubMed: 16526802]

5. (a) Batey RA, Thadani AN. Org Lett 1999;1:1683-1686. (b) Pucheault M, Darses S, Genêt J-P. Tetrahedron Lett 2002;43:6155-6157. (c) Pucheault M, Darses S, Genêt J-P. Eur J Org Chem 2002:3552-3557. (d) Navarre L, Pucheault M, Darses S, Genêt J-P. Tetrahedron Lett 2005;46:42474250.

6. (a) Batey RA, Thadani AN, Smil DV. Tetrahedron Lett 1999;40:4289-4292. (b) Batey RA, Thadani AN, Smil DV. Synthesis 2000:990-998. (c) Thadani AN, Batey RA. Org Lett 2002;4:3827-3830. [PubMed: 12599469] (d) Thadani AN, Batey RA. Tetrahedron Lett 2003;44:8051-8055.

7. Li S-W, Batey RA. Chem Commun 2004;12:1382-1383.

8. (a) Vedejs E, Chapman RW, Fields SC, Lin S, Schrimpf MR. J Org Chem 1995;60:3020-3027. (b) Vedejs E, Fields SC, Hayashi R, Hitchcock SR, Powell DR, Schrimpf MR. J Am Chem Soc 1999;121:2460-2470.

9. Genêt J-P, Darses S, Brayer J-L, Demoute J-P. Tetrahedron Lett 1997;38:4393-4396.

10. Korneev SM, Kaufmann DE. Synthesis 2002:491-496.

11. Flash chromatography using $\mathrm{CHCl}_{3}$ with $\mathrm{MeOH}$ or $\mathrm{MeCN}$ was tried in an attempt to purify the tetrabutylammonium organotrifluoroborates. With the exception of one or two compounds, attempts at $\mathrm{SiO}_{2}$ chromatography using this solvent system resulted in decomposition of the trifluoroborates to the corresponding boronic acids as indicated by ${ }^{11} \mathrm{~B}$ NMR.

12. Molander GA, Biolatto B. Org Lett 2002;4:1867-1870. [PubMed: 12027634] 

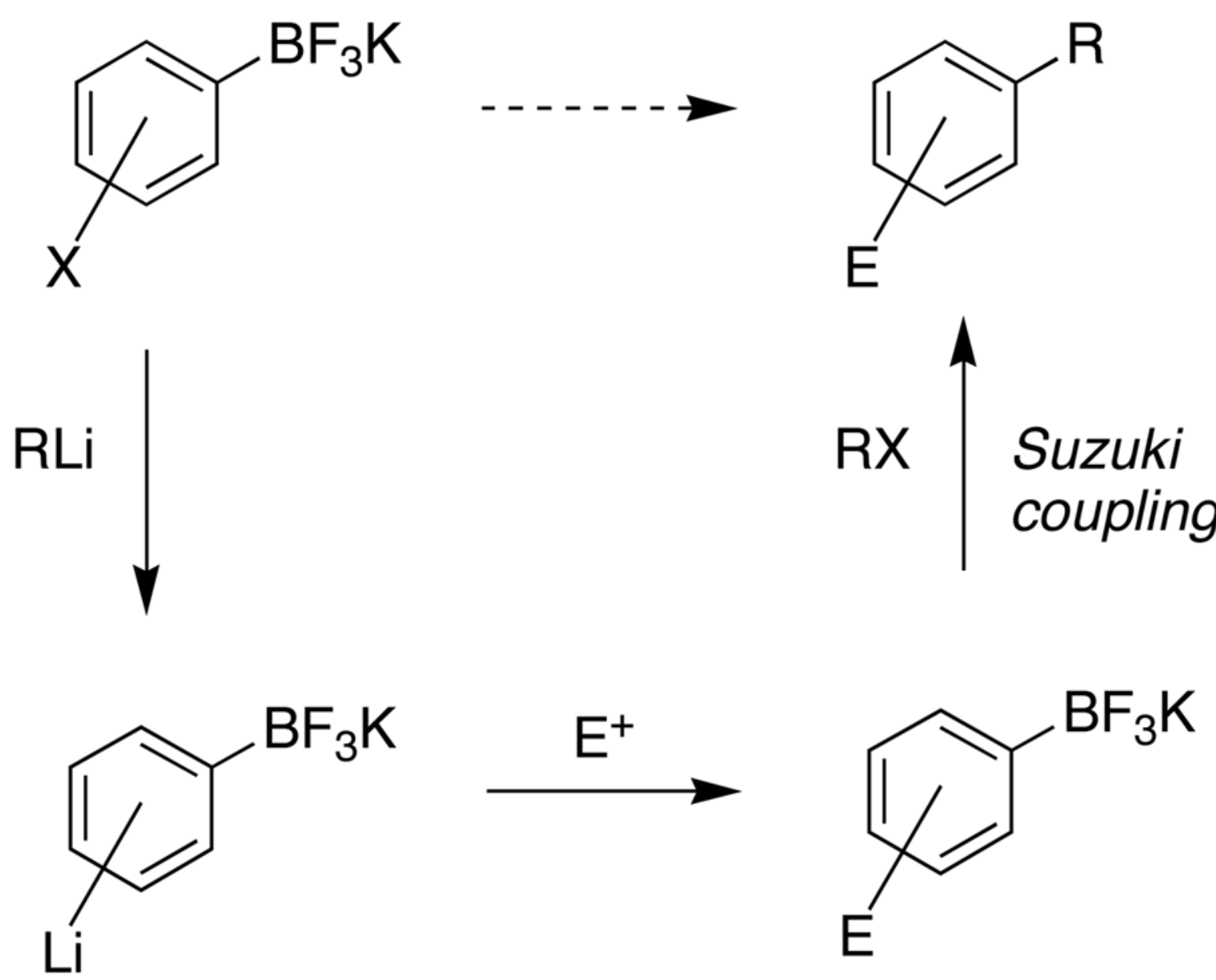

Scheme 1.
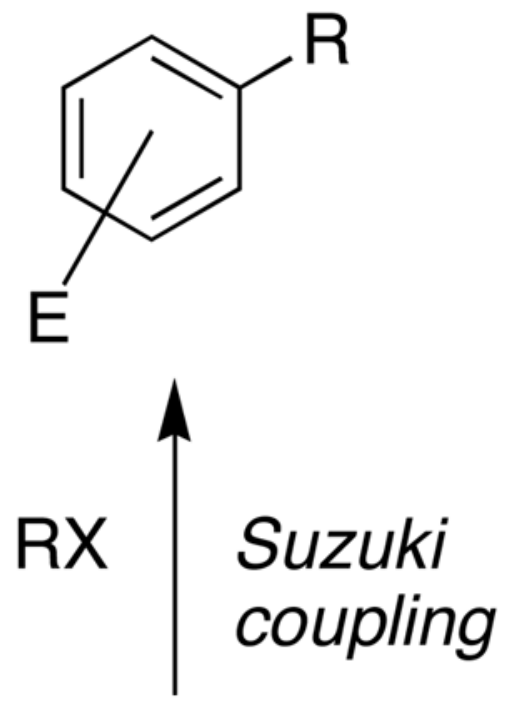


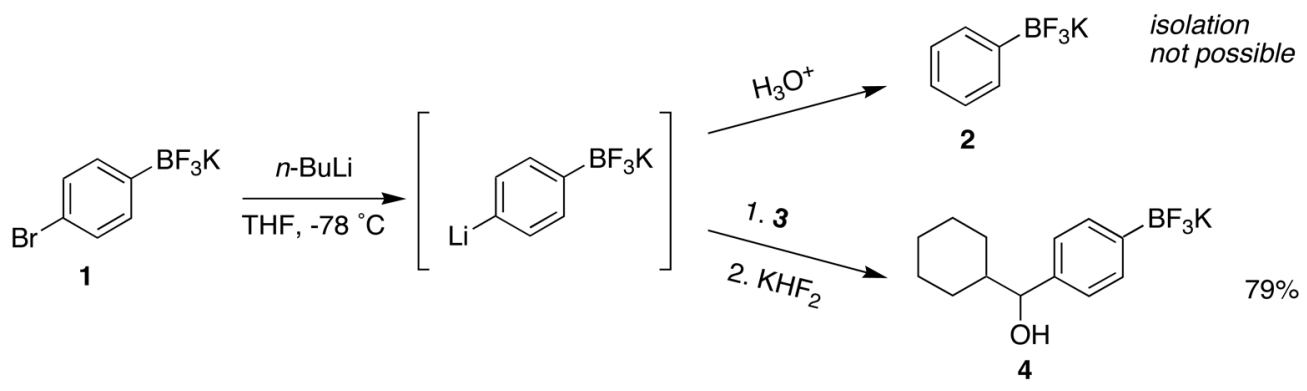

Scheme 2. 
Table 1

Variation of the Duration of Lithium-Halogen Exchange

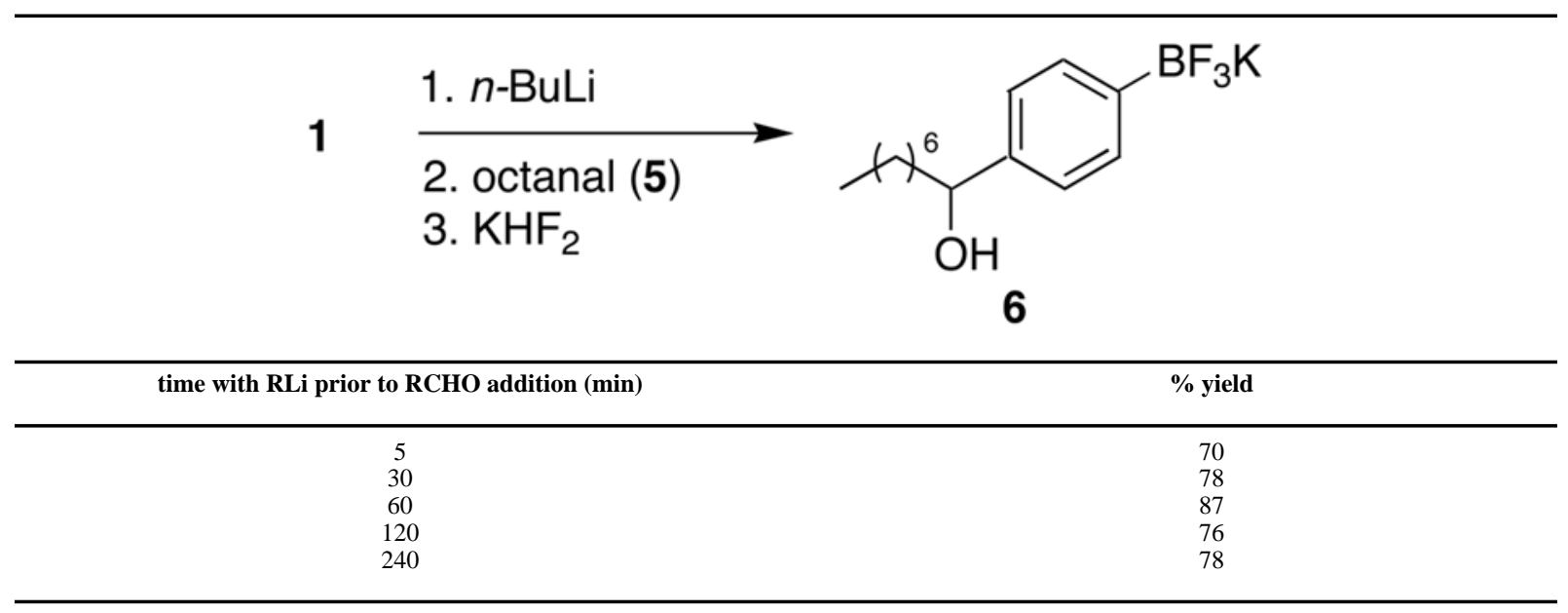


Table 2

Optimized Lithium-Halogen Exchange Reactions of $p$-Bromophenyl Trifluoroborate (1)
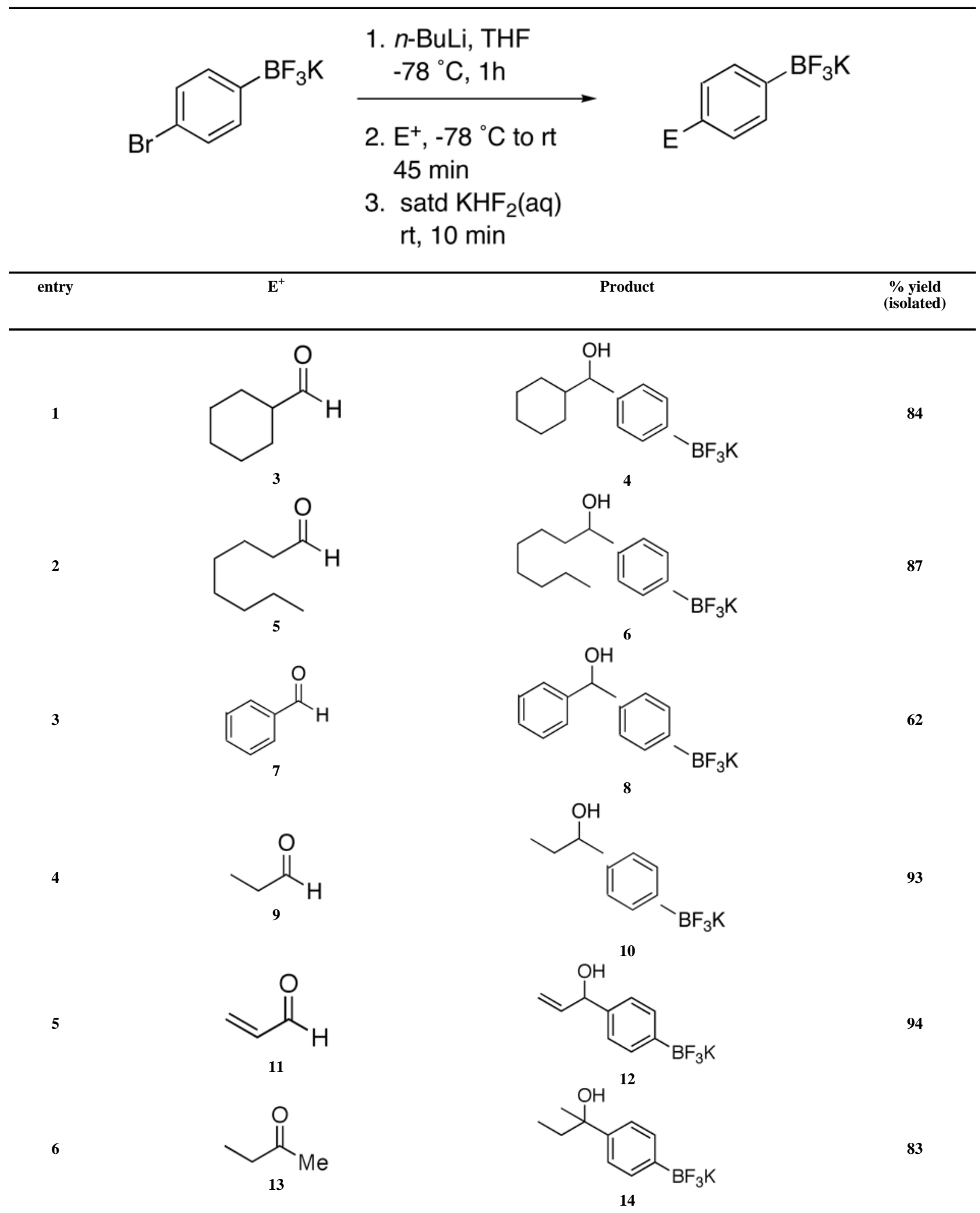

J Org Chem. Author manuscript; available in PMC 2008 August 8. 


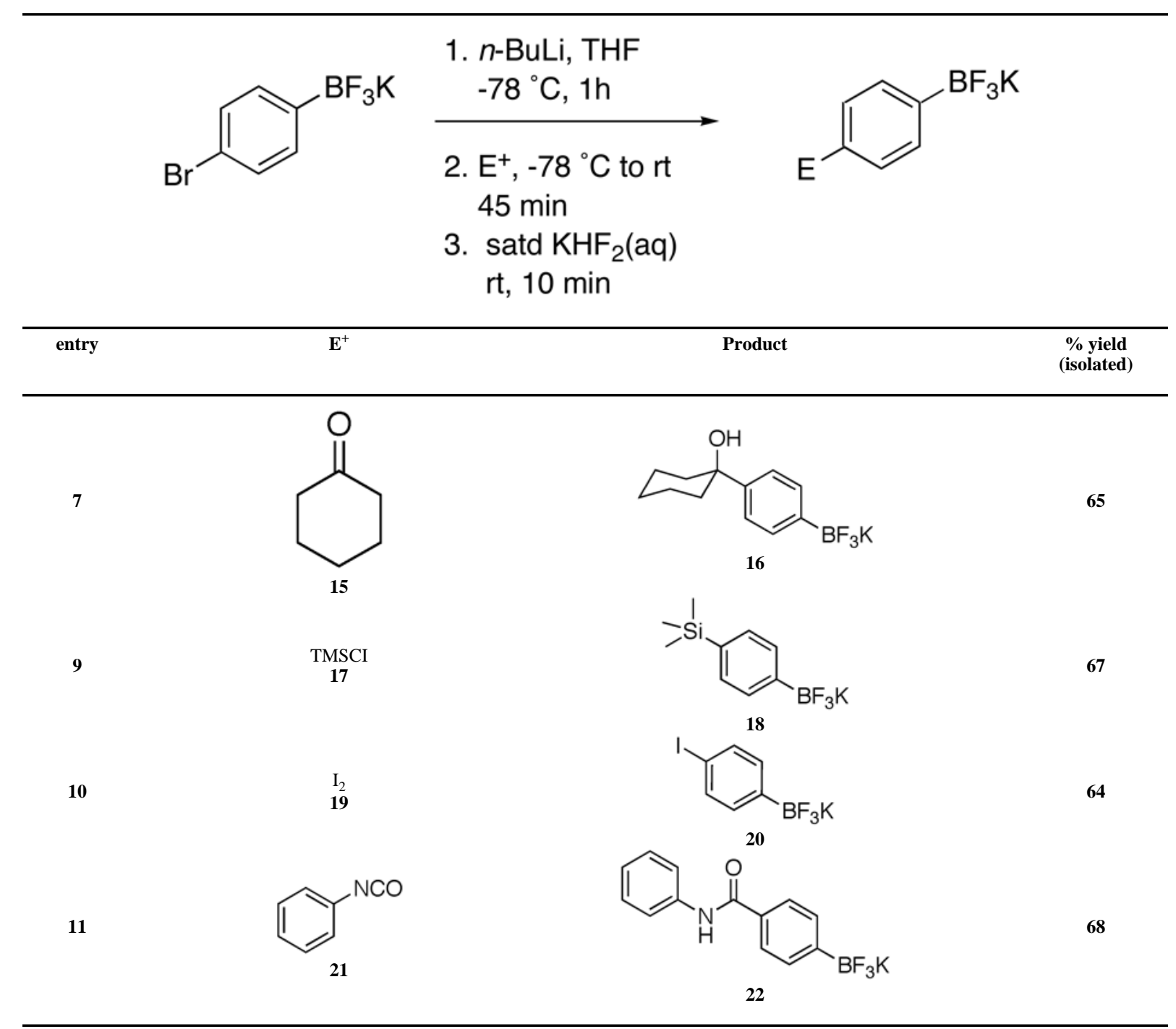

